\title{
Relational Uncertainty, Perceived Fairness, and the Division of Household Labor in Cohabiting and Married Couples
}

\author{
Yen-Chi Le ${ }^{1}$ \\ Center for Health Promotion \& Prevention Research, School of Public Health, \\ University of Texas Health Science Center at Houston, Houston, Texas \\ Krystyna S. Aune \\ Academic Affairs, University of Hawaii at Manoa, Honolulu, Hawaii
}

\begin{abstract}
This study examined the relationship between relational uncertainty and perceptions of division of household labor (DHL) in cohabiting and married couples. Specifically, research questions explored perceived fairness in DHL and relational uncertainty, perceptual convergence of contributions, convergence of perceptions and relational uncertainty, and convergence of perceptions and relationship satisfaction. A behavioral methodology called the Household Portrait Technique was employed to examine how couples discuss how they decide who does what in the household. A total of 33 couples independently completed a self-report instrument and jointly participated in the Household Portrait activity. Results showed that husbands and wives were agreed in their perceptions of fairness. Couples agreed that husbands do more of the outdoor work and automobile maintenance whereas wives do more of the childcare. Convergent perceptions regarding DHL was positively associated with relational certainty and marginally associated with relationship satisfaction.
\end{abstract}

Keywords: relational uncertainty; perceived fairness; division of household labor; couples

The division of household labor is a salient issue for many individuals in cohabiting and marital relationships. With the increase in dual-earner and dual-career couples, family life has changed dramatically. More active involvement of men in parenting has evolved and yet the division of household labor still generally follows gender-typed patterns (Himsel \& Goldberg, 2003). The bulk of household labor has remained the primary responsibility of women (Benin \& Agostinelli, 1988; Ferree, 1991; Shelton \& John, 1996). Research on the inequity in division of household labor

\footnotetext{
1 Address correspondence and reprint requests to: Yen-Chi Le, Ph.D - Center for Health Promotion and Prevention Research, School of Public Health, University of Texas Health Science Center at Houston, 7000 Fannin, UCT 2664, Houston, TX 77030, Office: (713) 500-9622, Fax: (713) 500-9602, E-mail: yenchi.le@gmail.com

Acknowledgments: This study was funded by a grant from the College of Arts and Sciences Advisory Council at the University of Hawaii at Manoa. Dr. Le was supported during the manuscript revision process by the National Cancer Institute (NCI) /National Institutes of Health (NIH) (\#2R25 CA57712). The authors would also like to express their appreciation to research assistants: Lacey Ethier, Angela McInvale, and Kenneth Uehara. Portions of this research were presented at the 2007 International Communication Association conference in San Francisco, CA, US. The content is solely the responsibility of the authors and does not represent the official views of the NCI or NIH.
} 
has consistently found that: a) women perform about twice as much labor as men; and b) women have qualitatively different duties than men (Blair \& Johnson, 1992).

Much of the research on the division of household labor has examined the impact of inequity on marital satisfaction (Benin \& Agostinelli, 1988). Perception of fairness in the division of household labor has been associated with marital happiness and satisfaction (Stevens, Kiger, \& Riley, 2001). Equity theory (Walster, Walster, \& Berscheid, 1978) posits that individuals are happiest in relationships where rewards and costs of the relationship are proportional. When contributions exceed benefits, inequity and distress results. If persistent and not remedied, partners who experience inequity may experience relationship dissatisfaction.

While research on the division of household labor has established the persistent pattern of injustice with women contributing a greater share of effort (Freudenthaler \& Milula, 1998; Mikula, 1998) and investigated possible explanations for this inequity (Greenstein, 2000; Kamo, 1988), research has not yet examined the impact of relational uncertainty on perceived fairness in the division of household labor.

An Uncertainty Reduction Theory framework (Berger \& Calabrese, 1975; Berger, 1988) has been invoked by a number of relational scholars to explain numerous processes in relationship development including interference (Solomon \& Knobloch, 2001), turbulence (Solomon \& Knobloch , 2004), relational information processing (Knobloch \& Solomon, 2005), topic avoidance (Afifi \& Burgoon, 1998; Knobloch \& Carpenter-Theune, 2004), and jealousy experience and expression (Afifi \& Reichert, 1996). Relational uncertainty, specifically, is the degree of confidence people have in their perceptions of involvement in interpersonal relationships (Knobloch, 2005, p. 60). Relational uncertainty encompasses perceptions of one's own relational involvement, partner's involvement, and the nature of the relationship itself (Knobloch, 2005; Knobloch \& Solomon, 2002). Given the inherent relationships between relational uncertainty and relational thoughts and feelings, the present study is designed to examine the associations between relational uncertainty, perceptions of the division of household labor, and relationship satisfaction. At the outset, equity theory is presented, and previous research examining the division of household labor and relational uncertainty are reviewed. 


\section{Equity Theory}

Walster, Walster \& Berscheid (1978) proposed equity theory which states that individuals are happiest in relationships in which they feel they are receiving positive benefits that are proportional to the amount they contribute to the relationship, relative to their partner. Relationship equity is based upon this perception of fairness and not necessarily on absolute relationship equality. Thus, it is possible that a relationship is equitable even when one person contributes to the relationship more and consequently reaps more benefits from the relationship as long as the ratio is proportional to the partner.

Inequity is perceived when benefits received are not proportional to contributions made to the relationship (Walster, Walster \& Berscheid, 1978). Equity theory predicts that underbenefited and overbenefited partners will feel distress and will consequently work towards restoring equity to the relationship. It is evident that underbenefited partners would strive towards restoring equity, but less clear why overbenefited partners would want to restore equity. Traditional social exchange theory states that individuals try to maximize their outcomes while minimizing their costs. Some equity theorists suggest that equity is a social norm, thus overbenefited partners feel uncomfortable. Yet, research on extramarital affairs and relationship contentment (Hatfield, Greenberger, Traupmann \& Lambert, 1982; Traupmann, Hatfield \& Wexler, 1978) and research on newlyweds' marital satisfaction (Utne, Hatfield, Traupmann \& Greenberger, 1984) has found that overbenefited partners have levels of satisfaction and contentment more similar to partners in equitable relationships.

\section{Division of Household Labor}

Research on inequity in division of household labor, however, has not produced clear and consistent findings. The elusive relationship between the division of household labor and relationship satisfaction may be due to several factors. The notion of a "satisfactory" division of household labor is socially constructed (Stevens et al., 2001). Women's expectations of their partner's contributions may vary considerably. Some may simply desire “minimal participation” (Benin \& Agostinelli, 1988, p. 350), whereas others may desire equity. Beyond "wants," the source of comparisons made have been found to influence women's sense of fairness (Freudenthaler \& Mikula, 
1998). If women compare their partners' contributions to household labor to themselves, they might consider their situation unfair. However if the comparison is made to the household contributions of other men, and/or to traditional normative standards, a woman's own situation may not be perceived as unfair. Under such circumstances, the partner contributing less would not as likely be blamed for the inequity, and there would be less of a sense of entitlement (Freudenthaler \& Mikula, 1998).

Resource-bargaining theories suggest that traditional division of household labor may be viewed as fair if the male is the breadwinner and the female takes care of the home. Women may take other factors into account when assessing the equity in the division of household labor, such as employment outside the home or other resources the partner contributes to the family (Freudenthaler \& Mikula, 1998). However wives' employment is associated with only a minimal increase in husbands' contribution to household labor (Stevens et al., 2001).

Ideological factors regarding sex roles have not been found to be consistently related to perceptions of fairness (Stevens et al., 2001). Blair and Johnson (1992) found that gender ideology was not central to women's reactions to their partners' contribution to household labor. However Blair and Johnson (1992) did find that appreciation was a major predictor of perceptions of fairness. This may reflect the notion that housework may be a symbolic representation of caring, of taking care of the needs of loved ones (Stevens et al., 2001).

The aforementioned factors have largely focused on the individual, specifically expectations regarding contributions, evaluations of contributions (self and other's), and perceptions of equity and/or fairness. However what is lacking is the examination of dyadic factors that might impact perceived fairness and satisfaction. Specifically, this study examines the construct of relational uncertainty as a potential factor influencing the division of household labor. Also, the relative convergence of perceptions of the division of household labor is examined to see whether discrepancies exist, and if so, whether they impact relationship satisfaction. 


\section{Relational Uncertainty}

While Berger and Calabrese's (1975) original formulation of Uncertainty Reduction Theory was originally devised to explain the initial entry stage of interpersonal interaction, later reformulations (Berger, 1988) and extensions of the theory (Sunnafrank, 1986) have been applied to more developed relationships (Planalp \& Honeycutt, 1985). Relationship uncertainty is particularly evident beyond early relationship stages (Solomon \& Knobloch, 2001), and is the foundation for turbulence in middle stages of relationship development (Solomon \& Knobloch, 2004).

Knobloch and Solomon (2005) found a positive association between relational uncertainty and people's perceptions of interaction difficulty. These findings were consistent with findings by Knobloch and Carpenter-Theune (2004). While they predicted that topic avoidance and relationship threat would peak during middle stages of relationship development, a negative linear association was found, with most relationship damage attributed to communicating about avoided topics at initial stages of relationship development.

To more adequately assess relationship uncertainty (as opposed to previous measures of predictability of a partner's behaviors or partner's commitment to the relationship), Solomon and Knobloch (2001) created a self-report measure. Four facets of relationship uncertainty are assessed, including: behavioral norms, the future of the relationship, mutuality of involvement in the relationship, and the current definition of the relationship. They predicted a curvilinear relationship, but Solomon and Knobloch (2001) again found a negative linear correlation between intimacy and relationship uncertainty. So it seems that as relationships develop, uncertainty generally decreases concomitantly with increases in intimacy and commitment. The question remains as to how the reduction of uncertainty and increase in intimacy influence the degree to which perceptions of contributions and fairness in the division of household labor converge.

It may be that relational uncertainty precludes discussion of and negotiation of the division of household labor. Or, conversely, it may be that dissatisfaction with the division of household labor renders individuals less certain about their partners' level of involvement in the relationship, mutuality, the future, and behavioral norms. Regardless of the direction of this relationship, our first research question asks: $R Q 1: I S$ relational uncertainty associated with perceived fairness in the division of household labor? 
A related issue involves a comparison of perceptions of who does what in the home. It seems reasonable to assume that the closer partners' perceptions of the contributions to household chores are to one another, the less they experience relational uncertainty especially regarding behavioral norms. However agreement regarding who does what may not necessarily reflect satisfaction regarding the situation. Even though both partners may agree on who does what, there may be inequities in the division of household labor that may lead partners to question the future of the relationship, mutuality of involvement in the relationship, and the current definition of the relationship. The following research questions address the issues of perceptual convergence, relational uncertainty, and relationship satisfaction. RQ2: How do partners' perceptions compare on contributions to household labor? RQ3: Is convergence of perceptions regarding division of household labor associated with relational uncertainty? RQ4: Is convergence of perceptions regarding division of household labor associated with relationship satisfaction?

\section{Method}

\section{Participants}

Couples were recruited through newspaper advertisements, flyers, craigslist.com, and the graduate student organization listserve. In order to participate in the study, participants had to be at least eighteen years of age, be in a heterosexual cohabiting or married relationship, and residing in the same household. Participants received $\$ 10$ each, $\$ 20$ per couple to compensate them for their time.

The sample consisted of 33 couples. Twenty-four percent of participants were cohabiting $(n=8)$, while $76 \%$ of couples were married $(n=25)$. On average, cohabitors had been living together 1.66 years $(\mathrm{SD}=1.54)$ while married couples had been living together for 6.85 years $(\mathrm{SD}=7.61$ years). Participants ranged in age from 21 years to 62 years with a mean age of 31.47 years $(\mathrm{SD}=9.11)$. The sample of participants was ethnically diverse: $54.5 \%$ Caucasian, $15.2 \%$ Japanese, 6.1\% Chinese, 3.0\% Filipino, 1.5\% African American, 1.5\% Hawaiian/part-Hawaiian, and 18\% mixed/other. Most participants had at least a college degree and the average household income was $\$ 65,000$. Cohabiting and married couples were not significantly different in 
demographics except for household income. Married couples' average individual salaries were between $\$ 25,000-49,999$ whereas cohabiting couples' average individual salaries were between $\$ 15,001-24,999$.

\section{Procedure}

The study consisted of three parts. First, participants individually completed an eight-page questionnaire. Second, couples were instructed to collaboratively complete a videotaped activity called the Household Portrait Technique (Doucet, 2001). Doucet (2001) developed the dyadic methodology which is an activity that engages couples to lay all their cards on the table, literally. Household tasks such as vacuuming, doing dishes, taking out the trash, etc. are written onto individual cards. Couples were asked to place each card under one of the five columns to show who usually executes the task. The five columns were: woman, woman with man helping, shared equally, man with woman helping, and man. This technique requires collaboration and discussion regarding how chores are accomplished.

After completing the HPT, participants answered questions asked by the researcher. These data are not reported in this paper.

Instrument. A multi-part survey was developed for the purpose of this study using previously validated measures as well as new measures to assess variables unique to this investigation.

Fairness of Household Chores. A nine item scale developed by Blair and Lichter (1991) was modified and used to measure the extent of fairness on household chores (meal preparation/cooking, dishes, ironing/washing, outdoor tasks, shopping, auto maintenance, bills/finances, and childcare if applicable). Each item was scored on a 5point Likert-type scale with 1 being "very unfair to my partner" and 5 being "very unfair to me."

Responsibility of Household Chores. A nine item scale developed by Blair and Lichter (1991) was modified and used to measure the extent of responsibility on household chores (meal preparation/cooking, dishes, ironing/washing, outdoor tasks, shopping, auto maintenance, bills/finances, and childcare if applicable). Each item was scored on a 5-point Likert-type scale with 1 being "my partner is solely responsible" and 5 being "I am solely responsible." 
Relationship Satisfaction. Norton's (1983) Quality of Marriage Index was used to measure overall relationship satisfaction. The scale was modified to be applicable to both cohabiting and married relationships. The final scale included five Likert-type items anchored by 1 "very strong disagreement" and 7 "very strong agreement." Alpha reliability obtained in this sample was .92 .

Relational Uncertainty. Solomon and Knobloch $=\mathrm{s}$ (2001) scale to assess the four distinct facets of relationship uncertainty was used. Four items assessed uncertainty about behavioral norms. Alpha reliability was .89. Four items assessed uncertainty about the future. Alpha reliability was .92. Three items assessed uncertainty about mutuality (alpha $=.89$ ), and four items assessed uncertainty about the current definition (alpha $=.91)$. The alpha for relationship uncertainty overall was .95 .

Hatfield's Global Equity Measure. Hatfield's (1978) single-item measure of equity was used to measure global equity in the relationship. Participants were asked, "Considering what you put into your relationship compared to what you get out of it . . and what your partner puts in compared to what he or she gets out of it, how does your relationship “stack up?"”,

Perceived Importance of Fairness. To assess the importance of relationship fairness, participants were asked, "How important is it for you that your current romantic relationship is fair (i.e., both of you contribute equally)?" This item was originally developed by Walster (now Hatfield) (1978) and was used in conjuction with the global relationship equity measure. This seven point Likert-type item was anchored using 1 "Not at all" and 7 "Very important."

Contribution of Household Labor Relative to Participant. To assess the participants' perception of fairness in household tasks, participants were asked, "How much housework does your partner do, compared to you?" The Likert-type item was anchored using 1 "I do more" and 7 "My partner does more."

Social Comparison of Household Labor. To assess how participants perceived their partner's contribution to household labor, relative to the other partners of the same sex, participants were asked, "How much housework does your partner do, compared to other men (if your partner is male) or women (if your partner is female)?" The Likert-type item was anchored using 1 "My partner does more" and 7 "Others do more." 


\section{Results}

\section{Descriptive Data}

Overall, there were no significant differences in couples' ratings of relationship satisfaction and relationship equity. Husbands' average ratings of relationship satisfaction was $6.32(S D=0.70)$ and wives' average ratings of relationship satisfaction was $6.30(S D=0.93)$. Similarly, ratings for relationship equity were similar for husbands $(M=4.15, S D=0.75)$ and for wives $(M=4.33, S D=0.94)$.

\section{Research Question 1}

The first research question asked whether relational uncertainty is associated with perceived fairness in the Division of Household Labor. Pearson Product Moment Correlations were computed between perceived fairness and each of the dimensions of relational uncertainty.

Individual Ratings of Household Labor Fairness. Couples' individual ratings of fairness of household labor included responsibility for cleaning, cooking, auto repair, childcare, ironing/washing laundry, shopping and bills/finances. See Table 1 for means and standard deviations. Paired t-tests on each item showed that couples' individual ratings of fairness were not significantly different, except for one item: shopping. In other words, husbands and wives were accurate in their perceptions of fairness. The responsibility for cooking, washing dishes, cleaning, ironing and folding, bills and finance were considered to be shared equally. However, couples agreed that husbands do more of the outdoor work and automobile maintenance whereas wives do more of the childcare. Couples differed in their perceptions of fairness for shopping. Both men $(M=2.97, S D=.31)$ and women $(M=3.18, S D=.47)$ thought that shopping was slightly unfair to them, $t(32)=-2.23, p<.05$. 
Table 1. Means and Standard Deviations of Ratings of Fairness of Household Labor

\begin{tabular}{l|l|r|r|r|r}
\hline \multirow{2}{*}{} & & Mean & $\mathrm{N}$ & Std. Deviation & \multicolumn{2}{c}{$\begin{array}{c}\text { Std. Error } \\
\text { Mean }\end{array}$} \\
\hline \multirow{2}{*}{$\begin{array}{l}\text { Meals/ } \\
\text { Cook }\end{array}$} & Male & 2.97 & 33 & .585 & .102 \\
\cline { 2 - 7 } & Female & 2.82 & 33 & .683 & .119 \\
\hline \multirow{2}{*}{ Dishes } & Male & 3.06 & 33 & .496 & .086 \\
\cline { 2 - 7 } & Female & 2.88 & 33 & .650 & .113 \\
\hline Clean & Male & 2.91 & 33 & .522 & .091 \\
\cline { 2 - 7 } & Female & 2.94 & 33 & .747 & .130 \\
\hline \multirow{2}{*}{ Wash/ } & Male & 2.94 & 33 & .609 & .106 \\
\cline { 2 - 7 } & Female & 2.85 & 33 & .508 & .088 \\
\hline \multirow{2}{*}{ Outdoor } & Male & 3.04 & 27 & .437 & .084 \\
\cline { 2 - 7 } & Female & 2.74 & 27 & .526 & .101 \\
\hline \multirow{3}{*}{ Shop } & Male & 2.97 & 33 & .305 & .053 \\
\cline { 2 - 7 } & Female & 3.18 & 33 & .465 & .081 \\
\hline \multirow{2}{*}{$\begin{array}{l}\text { Auto } \\
\text { Maintain }\end{array}$} & Male & 3.16 & 32 & .574 & .101 \\
\cline { 2 - 7 } & Female & 2.94 & 32 & .435 & .077 \\
\hline \multirow{2}{*}{ Bills } & Male & 2.79 & 33 & .600 & .104 \\
\cline { 2 - 7 } & Female & 2.94 & 33 & .496 & .086 \\
\hline \multirow{2}{*}{ Childcare } & Male & 2.40 & 5 & .548 & .245 \\
\cline { 2 - 7 } & Female & 3.20 & 5 & .837 & .374 \\
\hline
\end{tabular}

The nine fairness items were averaged to form a single-item perceived fairness score to be used for correlation analyses with relational uncertainty.

Women. For women, perceived fairness was significantly negatively associated with relational uncertainty regarding behavioral norms, $r(33)=-.37, p<.05$, and mutuality $r(33)=$

$-.35, p<.05$. Surprisingly, perceived fairness was not significantly associated with current state of the relationship or future.

Men. For men, perceived fairness was not significantly associated with any of the four dimensions of relational uncertainty.

\section{Research Question 2}

The second research question asked how partners' perceptions compare on contributions to household labor. 


\section{Le \& Aune}

Individual Ratings of Household Labor Responsibility. Couples' individual ratings of responsibility for cleaning, cooking, auto repair, childcare, ironing/washing laundry, shopping and bills/finances. Paired t-tests on each item showed that couples' individual ratings were not significantly different. In other words, husbands and wives are accurate in their perceptions of responsibility and their perceptions of fairness. The responsibility for cooking, washing dishes, cleaning, ironing and folding, shopping, bills and finance were considered to be shared equally. However, couples agreed that husbands do more of the outdoor work and automobile maintenance whereas wives do more of the childcare. See Table 2 for means and standard deviations of perceived responsibility for individual chores.

Table 2. Means and Standard Deviations of Ratings of Contributions to Household Labor

\begin{tabular}{l|l|r|r|r|r}
\hline \multicolumn{2}{c}{} & & & & \multicolumn{2}{c}{$\begin{array}{c}\text { Std. Error } \\
\text { Mean }\end{array}$} \\
\hline \multirow{2}{*}{$\begin{array}{l}\text { Meals/ } \\
\text { Cook }\end{array}$} & Female & Mean & Std. Deviation & .174 \\
\cline { 2 - 6 } & Male & 3.00 & 33 & 1.000 & .190 \\
\hline \multirow{2}{*}{ Dishes } & Female & 3.00 & 33 & 1.090 & .181 \\
\cline { 2 - 6 } & Male & 3.09 & 33 & 1.042 & .183 \\
\hline \multirow{2}{*}{ Clean } & Female & 2.88 & 33 & 1.053 & .138 \\
\cline { 2 - 6 } & Male & 3.24 & 33 & .792 & .131 \\
\hline \multirow{2}{*}{ Iron } & Female & 3.15 & 33 & .755 & .169 \\
\cline { 2 - 6 } & Male & 3.15 & 33 & .972 & .174 \\
\hline \multirow{3}{*}{ Outdoor } & Female & 3.06 & 33 & .998 & .189 \\
\cline { 2 - 6 } & Male & 2.26 & 27 & .984 & .169 \\
\hline \multirow{2}{*}{ Shop } & Female & 2.19 & 27 & .879 & .102 \\
\cline { 2 - 6 } & Male & 3.30 & 33 & .727 & .127 \\
\hline \multirow{2}{*}{$\begin{array}{l}\text { Auto } \\
\text { Maintain }\end{array}$} & Female & 3.18 & 33 & .914 & .162 \\
\cline { 2 - 6 } & Male & 2.06 & 32 & 1.008 & .178 \\
\hline \multirow{2}{*}{ Bills } & Female & 1.88 & 32 & 1.034 & .180 \\
\cline { 2 - 6 } & Male & 3.15 & 33 & 1.021 & .178 \\
\hline \multirow{2}{*}{ Childcare } & Female & 3.33 & 33 & .447 & .200 \\
\cline { 2 - 6 } & Male & 3.80 & 5 & .548 & .245 \\
\hline \multirow{2}{*}{} & & 3.60 & 5 & & \\
\hline
\end{tabular}

Individual ratings of weekly housework contribution of self and partner. Couples were also asked individually to estimate how many hours they spent on housework per week and how many hours their partners spent on housework per week. 
On average, men estimated their housework contribution as 5.91 hours $(S D=4.26)$, whereas men estimated their partners' contribution of housework to be 5.17 hours $(S D=$ 3.73). On average, women estimated doing about 5.70 hours $(S D=5.15)$ of housework and estimated their partners contributed 5.47 hours $(S D=5.97)$. Paired t-tests revealed no significant differences in estimations of weekly contributions of household labor.

Social comparison of household labor. Participants were asked to compare their partners' housework contributions to themselves and to their partners' reference groups (e.g., other men, other women). Men and women were not significantly different in their comparison of their partners' contributions, compared to their contributions. Although not significantly different, women and men both thought they contributed slightly more than their partners.

Men and women were significantly different in their ratings of their partners' contributions compared to the 'average' male or female, $t(32)=13.35, p<.01$. Women tended to rate their partners as doing slightly more $(M=5.27, S D=1.61)$ than the average male whereas men rated their partners as doing what the average female would do $(M=3.89, S D=1.46)$.

\section{Research Question 3}

The third research question asked whether convergence of perceptions regarding division of household labor is associated with relational uncertainty. To obtain a convergence of perceptions score, each partner's ratings for the nine household labor items were averaged to form an overall DHL score. Then, to assess convergence of perception of responsibility, the absolute difference between each partner's score was calculated. Relational uncertainty scores were assessed individually. Each couple's composite relational uncertainty scores were calculated in two steps. First, paired t-tests were conducted to examine if there were significant differences in the responses of male and female partners on the four relational uncertainty factors. No significant differences were found in individual ratings of behavioral norms, current state, future and mutuality. Thus, each partner's ratings were averaged to form a composite relational uncertainty rating.

Pearson-Product Moment Correlations were then computed using the absolute difference in household labor scores and the four relational uncertainty composite 
scores. Convergence of perception of DHL was significantly associated with current state, $r(33)=-.46, p<.01$, future, $r(33)=-.38, p<.05$, and mutuality, $r(33)=-.43, p<$ .05 . In other words, divergence in perception of DHL was associated with decreases in relational certainty concerning the current state of the relationship, the future state of the relationship, and mutuality. On the other hand, convergence of perception of DHL was not significantly associated with behavioral norms, $r(33)=-.29, n s(p=.09)$.

\section{Research Question 4}

The fourth research question asked whether convergence of perceptions regarding division of household labor is associated with relationship satisfaction. The absolute difference scores used in RQ3 were also used in RQ4. For purposes of analyses, a composite couple's relationship satisfaction score was calculated using each partner's individual satisfaction scores. A paired t-test showed no significant difference between the satisfaction ratings of both partners. A Pearson-Product Moment Correlation was then computed using the absolute difference in household labor scores and the composite relationship satisfaction scores. Convergence of perception of DHL was only marginally associated with relationship satisfaction, $r(33)=-.34, p=.056$.

\section{Discussion}

The purpose of this study was to examine the roles of relational uncertainty and perceptions of the division of household labor. An interesting behavioral methodology, the Household Portrait Technique, was employed to assess couples' assessment of housework. Couples independently and jointly provided open-ended and closed-ended data to answer the research questions.

The first research question examining the relationship between relational uncertainty and perceived fairness in the Division of Household Labor was tested using correlations. The results showed that for women, but not men, perceived fairness was significantly negatively associated with relational uncertainty regarding behavioral norms and mutuality. However, neither uncertainty regarding the current state of the relationship nor future of the relationship were associated with perceived fairness of division of household labor. It makes sense that greater perceived fairness would relate to certainty regarding behavioral norms and mutuality. Women who are experiencing 
equity would naturally think that they have worked out the division of household labor satisfactorily and that both partners are equally invested in the relationship.

It is interesting to note that uncertainty regarding the current state of the relationship and future of the relationship were not associated with perceived fairness in division of household labor for either women or men. It may be that fairness in division of household labor does not reflect uncertainty in the current state of the relationship (it may be the case that unfairness is related to certainty about the poor state of the relationship, for example). Likewise, fairness (or lack thereof) may be associated with certainty about the future of the relationship (or lack thereof).

For men, fairness in the division of household labor is not associated with any of the dimensions of relational uncertainty. While historically, men have been found to be over-benefited in terms of household labor, for the most part, couples in this study perceived that the division of household labor is relatively fair. It may be that cultural norms override these perceptions rendering relational uncertainty independent from division of household labor.

The second research question examined how partners' perceptions compare on contributions to household labor. No differences were found in partners' perceptions of responsibility of chores. Consistent with traditional sex role expectations, couples agreed that husbands do more of the outdoor work and automobile maintenance whereas wives do more of the childcare. While women estimated working slightly more in terms of hours per week than their husbands (.23 hours difference for women, and 8 hours difference for men), these differences were not significant. Overall estimates of amount of time per week spent on household labor were relatively low, however.

The positive bias exhibited by women is interesting to note. Women rated their partners as doing slightly more than the average male, while men rated their partners as doing what the average female would do. As noted earlier, women may over-value even small contributions by their partners. This is likely due to historical and widespread cultural expectations of the role of women as nurturers. Women's efforts may be less visible, less noteworthy or applause-worthy than men. Hence women's contributions are seen as normative by men.

The third research question regarding the relationship between perceptual convergence regarding contributions to household labor and relational uncertainty found that divergence in perception of DHL was associated with decreases in relational 
certainty concerning the current state of the relationship, the future state of the relationship, and mutuality. So the closer partners' perceptions are regarding who does what housework, the greater confidence they feel about the relationship's state, future, and mutuality. Oddly, convergence of perceptions was only marginally associated with certainty regarding behavioral norms. This finding may be, in part, due to the relatively small sample size used in this study (dyadic analyses of 33 couples). Future research using a larger sample may delve further into this issue.

The fourth research question exploring whether convergence of DHL perceptions is associated with relationship satisfaction found only a marginal correlation (.056). This, too, may be an artifact of the small sample size obtained in this study. Furthermore, most couples in this study did not have children. Only 6 of the 33 couples reported having children (precluding any meaningful statistical comparison between the two groups). This may play a significant role in the importance of equity in division of household labor. According to LePoire (2006), new parents' household tasks increase six-fold after the birth of a child. For new mothers, their workload increases from 5.3 to 28 tasks per day, whereas fathers' workload only increases from 2.4 to 8.3 tasks per day (LePoire, 2006). Given that the sample was largely childless, relatively satisfied, and perceived an equitable distribution of household labor, it may not be surprising that relationship satisfaction was not significantly associated with convergent perceptions of DHL.

Relational Uncertainty appears to be a useful construct to investigate in the context of household labor. While this study did not predict or test causal directionality, it would be useful to investigate which factor is antecedent. Does inequity in division of household labor lead to greater uncertainty regarding behavioral norms, mutuality, the current state of the relationship, and the future of the relationship? And if so, are there differential effects across the dimensions of uncertainty? Or, does relational uncertainty predict lack of convergence of perceptions and/or inequity in DHL.

A strength of this study was the multiple-methodologies used. We were able to compare self-report (individual) ratings, to collaboratively derived ratings of their division of household labor. For the most part, our respondents' individual ratings did not significantly differ from collaborative responses. It would be useful to examine perceptual convergence among a more heterogeneous sample comprised of individuals who have less satisfying relationships, and/or of lower socio-economic status. Combining quantitative with qualitative data will undoubtedly provide a richer, more 
complete picture of the process of negotiating the division of household labor. Given how ubiquitous and salient the issue of household labor is for many couples, continued investigation of this issue is warranted.

\section{References}

Affifi, W. A., \& Burgoon, J. K. (1998). AWe never talk about that@: A comparison of cross-sex friendships and dating relationships on uncertainty and topic avoidance. Personal Relationships, 5, 255-272.

Affifi, W. A., \& Reichert, T. (1996). Understanding the role of uncertainty in jealousy experience and expression. Communication Reports, 9, 93-103.

Altman, I., \& Taylor, D. A. (1973). Social penetration: The development of interpersonal relationships. New York: Holt, Rinehart, \& Winston.

Benin, M.H. \& Agostinelli, J. (1988). Husbands' and wives' satisfaction with the division of labor. Journal of Marriage and the Family, 50, 349-362.

Berger, C. R. (1988). Uncertainty and information exchange in developing relationships. In S. Duck (Ed.), Handbook of personal relationships: Theory, research, and interventions (pp. 239-256). New York: Wiley.

Berger, C. R., \& Calabrese, R. J. (1975). Some explorations in initial interaction and beyond: Toward a developmental theory of interpersonal communication. Human Communication Research, 1, 99-112.

Blair, S. L. \& Johnson, M. P. (1992). Wives' perceptions of the fairness of the division of household labor: The intersection of housework and ideology. Journal of Marriage and the Family, 54, 570-581.

Doucet, A. (2001). "You see the need perhaps more clearly than I have:" exploring gendered processes of domestic responsibility. Journal of Family Issues, 22, 328-357.

Ferree, M. M. (1991). The Gender Division of Labor in Two-Earner Marriages: Dimensions of Variability and Change. Journal of Family Issues, 12, 158-180.

Freudenthaler, H. H. \& Mikula, G. (1998). From Unfulfilled Wants to the Experience of Injustice: Women's Sense of Injustice Regarding the Lopsided Division of Labor. Social Justice Research, 11, 289-303. 
Greenstein, T. N. (2000). Economic dependence, gender, and the division of labor in the home: A replication and extension. Journal of Marriage and the Family, 62, 322-336.

Himsel, A. J., \& Goldberg, W. A. (2003). Social comparisons and satisfaction with the division of housework: Implications for men's and women's role strain, Journal of Family Issues, 24, 843-866.

Kamo, Y. (1988). Determinants of household division of labor: Resources, power, and ideology. Journal of Family Issues, 9, 177-200.

Knobloch, L. K.. (2005). Evaluating a contextual model of responses to relational uncertainty increasing events: The role of intimacy, appraisals, and emotions. Human Communication Research, 31, 60-101.

Knobloch, L. K., \& Carpenter-Theune, K. E. (2004). Topic avoidance in developing romantic relationships: Associations with intimacy and relational uncertainty. Communication Research, 31, 173-205.

Knobloch, L. K., \& Solomon, D. H. (2002). Information seeking beyond initial interaction: Negotiating relational uncertainty within close relationships. Human Communication Research, 28, 243-257.

Knobloch, L. K., \& Solomon, D. H. (2005). Relational uncertainty and relational information processing: Questions without answers? Communication Research, 32, 349-388.

LePoire, B. A. (2006). Family communication: Nurturing and control in a changing world. Thousand Oaks, CA: Sage.

Mikula, G. (1998). Division of household labor and perceived justice: A growing field of research. Social Justice Research, 11, 215-241.

Mikula, G., Freudenthaler, H. H., Brennacher-Kröll, S., Schiller-Brandl, R. (1997). Arrangements and rules of distribution of burdens and duties: the case of household chores. European Journal of Social Psychology, 27, 189-209.

Norton, R. (1983). Measuring marital quality: A critical look at the dependent variable. Journal of Marriage and the Family, 45(1), 141-151.

Planalp, S., \& Honeycutt, J. M. (1985). Events that increase uncertainty in personal relationships. Human Communication Research, 11, 593-604.

Ross, C., Mirowsky, J., \& Huber, J. (1983). Dividing work, sharing work, and inbetween: Marriage patterns and depression, American Sociological Review, 48, 809-823. 
Shelton, B. A. \& John, D. (1996). Division of Household Labor. Annual Review of Sociology, 22, 299-322.

Solomon, D. H., \& Knobloch, L. K. (2001). Relationship uncertainty, partner interference, and intimacy within dating relationships. Journal of Social and Personal Relationships, 21, 795-816.

Solomon, D. H., \& Knobloch, L. K. (2004). A model of relational turbulence: The role of intimacy, relational uncertainty, and interference from partners in appraisals of irritations. Journal of Social and Personal Relationships, 21, 795-816.

Stevens, D., Kiger, G. \& Riley, P.J. (2001). Working Hard and Hardly Working: Domestic Labor and Marital Satisfaction Among Dual-Earner Couples. Journal of Marriage \& the Family, 63, 514-527,

Stohs, J.H. (2000). Multicultural Women's Experience of Household Labor, Conflicts, and Equity. Sex Roles, 42, 339-362.

Sunnafrank, M. (1986). Predicted outcome value during initial interactions: A reformulation of Uncertainty Reduction Theory. Human Communication Research, 13, 191-210.

Utne, M. K., Hatfield, E., Traupmann, J., \& Greenberger, D. (1984). Equity, marital satisfaction, and stability. Journal of Social and Personal Relationships, l, 323-332.

Walster (Hatfield), E., Traupmann, J., \& Walster, G. W. (1978). Equity and extramarital sexuality. Archives of Sexual Behavior, 7, 127-141.

Walster (Hatfield), E., Greenberger, D., Pillemer, J., \& Lambert, P. (1982). Equity and sexual satisfaction in recently married couples. The Journal of Sex Research, 18, $18-32$.

Walster(Hatfield), E., Walster, G. W. \& Berscheid, E. (1978). Equity: Theory and research. Boston: Allyn \& Bacon.

Received: February 19th, 2011

Accepted: December 30th, 2011 